\title{
Contract Consolidation in Medicare Advantage: 2006-2016
}

\author{
David J. Meyers, MPH॰, Momotazur Rahman, PhD, Ira B. Wilson, MD, MS, FACP, \\ Vincent Mor, PhD, and Amal N. Trivedi, MD, MPH
}

Department of Health Services, Policy, and Practice, Brown University School of Public Health, Providence, RI, USA.

$\mathrm{J}$ Gen Intern Med 35(2):606-8

DOI: $10.1007 / \mathrm{s} 11606-019-05036-0$

() Society of General Internal Medicine 2019

\section{INTRODUCTION}

Over $33 \%$ of Medicare beneficiaries are enrolled in Medicare Advantage (MA). ${ }^{1}$ The MA Quality Improvement Program (QIP), which the Centers for Medicare and Medicaid Services (CMS) launched as a demonstration in 2012 and made permanent in 2014, rates all MA contracts from 2 to 5 stars based on quality measures. CMS rewards contracts rated 4+ stars with $5 \%$ per capita bonus payments and has paid over $\$ 3.1$ billion in bonuses annually.

Under CMS policy, an insurer with multiple MA contracts may consolidate all enrollees from a contract with a low star rating into another contract with a rating of $4+$ stars. $^{2}$ The insurer would then receive bonus payments for the transferred enrollees whether or not there were any changes to these enrollees' quality of care. The Medicare Payment and Advisory Commission described this practice as "an erosion of the integrity and utility of the tools used to measure quality." 3 We studied trends in MA contract consolidations and the characteristics of contracts and enrollees associated with consolidation from 2006 to 2016.

\section{METHODS}

The Medicare Beneficiary Summary File and the Healthcare Effectiveness and Information Data Set provided demographic characteristics and enrollment status. We defined a contract as consolidated if over $75 \%$ of enrollees move into a different contract owned by the same insurer in the following year, with the previous contract terminated. As a sensitivity check, we use CMS plan crosswalk files which report which contracts consolidated, and find similar trends.

We compared characteristics of the enrollees and contracts that were consolidated, those that were the destination following consolidation, and those that were neither using $\mathrm{chi}^{2}$ and ANOVA tests $(\alpha=0.05$, Stata 15$)$.

Prior Presentations There are no prior presentations to report.

Received April 1, 2019

Accepted April 11, 2019

Published online May 15, 2019
RESULTS

The study population included $28,496,847$ enrollees across 733 contracts from 2006 to 2016 . Figure 1 plots the annual number of consolidated contracts and the percentage of those consolidations that were to a contract with $4+$ stars. The number of consolidations and the proportion that were consolidated to 4+ stars increased after the QIP.

From 2012 to 2016, we estimate a cumulative 3,361,889 enrollees were in a consolidated contract, representing $11.8 \%$ of the MA population over this time period (Table 1). Of these, $2,599,783(77.3 \%)$ were consolidated from a lower-rated to a bonus-receiving contract. As compared with contracts that were not consolidated, consolidated contracts were more likely to be PPOs (55.2 vs. $22.9 \% ; p<0.001)$ and for-profit $(95.2 \%$ vs. $57.3 \% ; p<0.001)$. While $88.4 \%$ of the destination contracts were $4+, 54.8 \%$ of consolidated contracts were $<4$ stars.

Consolidated enrollees were less likely to be dual-eligible $(12.2 \%$ vs. $19.3 \% ; p<0.001)$, more likely to be white $(71.8 \%$ vs. $67.2 \% ; p<0.001)$, and living in the South $(48.5 \%$ vs. $29.8 \% ; p<0.001)$. Over $50 \%$ of all consolidated enrollees came from four insurers (UnitedHealthcare 25.9\%; Medica $10.0 \%$, Humana 9.1\%; Regence 5.2\%).

\section{DISCUSSION}

The QIP was accompanied by a substantial increase in contract consolidation in the MA program, affecting over $10 \%$ of MA enrollees from 2012 to 2016 . Consolidations primarily occurred from contracts rated $<4$ stars to those with $4+$ stars and were therefore eligible for bonuses, suggesting that this consolidation increased performance-based payments to MA insurers without requiring improved quality of care among enrollees who were transitioned. Some consolidations occurred before the launch of the QIP, which may be driven by other strategic goals such as reducing administrative costs; however, most consolidations occurred after the QIP. We build upon prior work ${ }^{2}$ by studying individual-level data before and after the QIP and the characteristics of contracts that engage in consolidation.

Following reports of this practice, CMS promulgated new regulations effective in 2020 that weigh the rating of the origin and destination contract when calculating bonuses. ${ }^{4}$ This policy may reduce incentives for insurers to "game" their bonus payments though consolidations. However, from 2012 to 


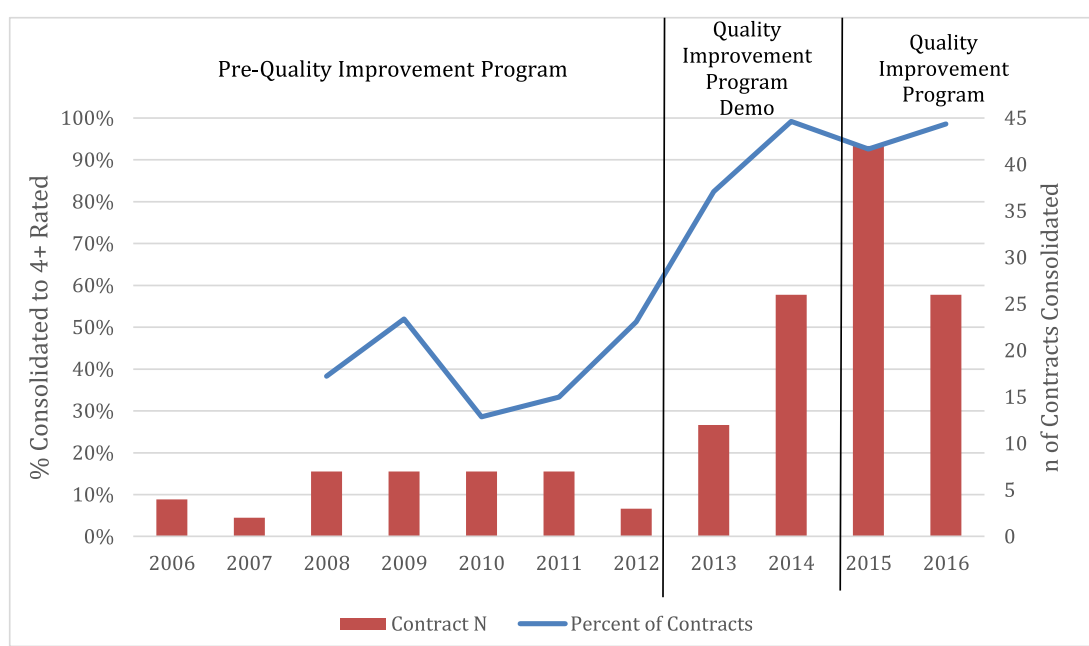

Figure 1 Number of consolidated contracts and proportion consolidated to 4+ stars, 2006-2016. The bars correspond to the right axis and represent the number of contracts that consolidate each year. The line corresponds to the left axis and is the percent of contracts that were consolidated to a 4+ star contract. Each year represents a consolidation from that year into the following (i.e., 2006 represents the number of 2006 contracts and enrollees who were consolidated into a different plan in 2007). The first bonuses were paid during the demo starting in 2012. The program was made permanent in 2014. Star ratings were launched in 2009, so the line graph is unavailable for $2006-2007$.

Table 1 Characteristics of People and Contracts Consolidated from 2012 to 2016

\begin{tabular}{|c|c|c|c|c|}
\hline Plan characteristic & $\begin{array}{l}\text { Consolidated } \\
n \text { (population weighted \%) }\end{array}$ & $\begin{array}{l}\text { Destination } \\
n \text { (population weighted } \%)\end{array}$ & $\begin{array}{l}\text { Neither } \\
n \text { (population weighted \%) }\end{array}$ & $p$ value \\
\hline$n$ of contracts & $128(18.3)$ & $73(28.8)$ & $532(52.8)$ & \\
\hline \multicolumn{5}{|l|}{ Type } \\
\hline $\mathrm{HMO}$ & $59(38.2)$ & $50(57.0)$ & $398(64.3)$ & \multirow{3}{*}{$<0.001$} \\
\hline PPO & $61(55.2)$ & $19(42.0)$ & $98(22.9)$ & \\
\hline Other & $7(6.6)$ & $2(1.0)$ & $34(12.8)$ & \\
\hline For profit & $111(95.2)$ & $47(84.2)$ & $227(57.3)$ & \multirow{2}{*}{$<0.001$} \\
\hline Star rating & $3.9(0.7)$ & $4.2(0.4)$ & $3.6(0.4)$ & \\
\hline Unrated & $17(0.6)$ & $9(0.6)$ & $210(6.3)$ & \multirow{4}{*}{$<0.001$} \\
\hline $2-2.5$ stars & $3(2.0)$ & $0(0)$ & $29(3.4)$ & \\
\hline 3-3.5 stars & $78(54.8)$ & $15(10.9)$ & $173(38.3)$ & \\
\hline $4-5$ stars & $30(42.7)$ & 49 (88.4) & $120(52.1)$ & \\
\hline Mean star rating $(\mathrm{sd})$ & $3.6(0.4)$ & $4.2(0.4)$ & $3.9(0.7)$ & $<0.001$ \\
\hline Mean $N$ counties in service area $(\mathrm{sd})$ & $220.3(366.7)$ & $133.9(150.1)$ & $287.6(708.2)$ & 0.625 \\
\hline Mean $N$ states in service area (sd) & $7.4(12.3)$ & $6.8(8.5)$ & $5.2(11.5)$ & 0.002 \\
\hline \multicolumn{5}{|l|}{ Service area category } \\
\hline Single state & $86(54.2)$ & $33(25.7)$ & $381(76.8)$ & \multirow[t]{3}{*}{$<0.001$} \\
\hline Regional ( $2-5$ states $)$ & $32(24.2)$ & $22(38.8)$ & $53(10.6)$ & \\
\hline National ( $>5$ states) & $10(21.6)$ & $18(35.6)$ & $98(12.7)$ & \\
\hline \multicolumn{5}{|l|}{ Plan size } \\
\hline Small $(0-5000)$ & $24(18.8)$ & $5(6.9)$ & $146(27.4)$ & \multirow[t]{3}{*}{$<0.001$} \\
\hline Medium $(500-25,000)$ & $55(43.0)$ & $17(23.3)$ & $161(30.3)$ & \\
\hline Large $(>25,000)$ & $49(38.3)$ & $51(69.9)$ & $225(42.3)$ & \\
\hline \multirow{2}{*}{ Enrollees' Characteristics } & $N(\%)$ & $N(\%)$ & $N(\%)$ & \multirow[t]{2}{*}{$p$ value } \\
\hline & $3,361,889$ & $8,170,716$ & $16,964,242$ & \\
\hline Mean age (sd) & $65.7(9.2)$ & $66.7(9.6)$ & $67(11.2)$ & $<0.001$ \\
\hline Female & $1,917,970(57.1)$ & $4,576,609(56.0)$ & $9,258,790(54.6)$ & $<0.001$ \\
\hline Dual eligibility & $410,053(12.2)$ & $1,115,690$ (13.7) & $3,267,422(19.3)$ & $<0.001$ \\
\hline \multicolumn{5}{|l|}{ Race/ethnicity } \\
\hline White & $2,413,213(71.8)$ & $5,737,864(70.3)$ & $11,225,861(67.2)$ & \multirow[t]{6}{*}{$<0.001$} \\
\hline Black & $461,411(13.7)$ & 927,219 (11.4) & $1,951,756(11.7)$ & \\
\hline Hispanic & $278,845(8.3)$ & $999,638(12.2)$ & $2,218,330$ (13.3) & \\
\hline Asian & $74,919(2.2)$ & $186,377(2.3)$ & $643,554(3.9)$ & \\
\hline NA/AI & $5838(0.2)$ & $11,850(0.2)$ & $38,475(0.2)$ & \\
\hline Other/unknown & $126,813(3.8)$ & $301,621(3.7)$ & $634,473(3.8)$ & \\
\hline \multicolumn{5}{|l|}{ Census region } \\
\hline Northeast & $318,196(9.6)$ & $1,069,288(13.6)$ & $3,888,068(23.9)$ & \multirow[t]{4}{*}{$<0.001$} \\
\hline Midwest & $777,712(23.5)$ & $2,317,187(29.5)$ & $2,710,945$ (16.7) & \\
\hline South & $1,608,275(48.5)$ & $2,910,067(37.0)$ & $4,838,546(29.8)$ & \\
\hline West & $609,385(18.4)$ & $1,567,233(19.9)$ & $4,823,107(29.7)$ & \\
\hline
\end{tabular}

$p$ values from $\mathrm{chi}^{2}$ or ANOVA tests as appropriate. Ns for contract characteristics represent contracts. Percentages in parentheses represent enrollment-weighed percentages for each characteristic. Ns and \%s for enrollee characteristics are individual level. Consolidated represents contracts that were eliminated and merged into another contract. Destination represents contracts that consolidated contracts were merged into. Neither represents contracts that were not consolidated at all during the time period. If a contract were terminated, and enrollees from that contract were not consolidated, that contract would be included in the Neither category. All characteristics are from the year before the consolidation occurred. Contract level data comes from publically available MA plan registry and characteristic files. Enrollee characteristics come from the Medicare Beneficiary Summary file. Characteristic level counts may not match overall counts due to missing data 
2016, assuming a $\$ 9000$ mean annual per capita payment for enrollees in consolidated contracts with $<4$ stars, we estimate that CMS may have paid out as much as $\$ 1.1$ billion in bonus payments for this population. Furthermore, this consolidation may undermine the accuracy of star ratings in MA and beneficiaries' ability to identify relative quality in making enrollment decisions. ${ }^{5}$ These findings highlight the need for CMS to anticipate and monitor unintended consequences of pay-forperformance initiatives including efforts to game quality ratings and bonus payments.

Corresponding Author: David J. Meyers, MPH; Department of Health Services, Policy, and Practice Brown University School of Public Health, Providence, RI, USA (e-mail: david_meyers@brown. $e d u$ ).

Contributors There were no other contributors beyond those included as authors.

Funders This work is supported in part by NIA P01AG027296.

\section{Compliance with Ethical Standards:}

Conflict of Interest: David J Meyers has no conflicts of interest to disclose.

Ira Wilson has no conflicts of interest to disclose.

Momotazur Rahman has no conflicts of interest to disclose.
Vincent Mor is the Chair of the Independent Quality Committee at HCR Manor Care, and Chair of the Scientific Advisory Board and consultant on NaviHealth Inc., as well as a former Director of PointRight Inc., where he holds less than 1\% equity.

Amal Trivedi has no conflicts of interest to disclose.

\section{REFERENCES}

1. Neuman P, Jacobson GA. Medicare advantage checkup. N Engl J Med. 2018;0(0):null. https://doi.org/10.1056/NEJMhpr 1804089.

2. Mathews AW, Weaver C. Insurers game medicare system to boost federal bonus payments. Wall Street J. https://www.wsj.com/articles/insurersgame-medicare-system-to-boost-federal-bonus-payments- 1520788658 . Published March 11, 2018. Accessed July 10, 2018.

3. Medicare Payment Advisory Commission. Report to the Congress: Medicare Payment Policy; 2018.

4. Center for Medicare and Medicaid Services. Announcement of Calendar Year (CY) 2019 Medicare Advantage Capitation Rates and Medicare Advantage and Part D Payment Policies and Final Call Letter. April 2018. h t t ps: / / www.cms.gov/Medicare/Health-Plans / MedicareAdvtgSpecRateStats/Downloads/Announcement2019.pdf. Accessed April 2, 2018.

5. Reid RO, Deb P, Howell BL, Conway PH, Shrank WH. The roles of cost and quality information in medicare advantage plan enrollment decisions: an observational study. J Gen Intern Med. 2016;31(2):234-241. https:// doi.org/10.1007/s11606-015-3467-3.

Publisher's Note Springer Nature remains neutral with regard to jurisdictional claims in published maps and institutional affiliations. 